\title{
Transformation of logistics methodology in the context of evolutionary and sustainable development
}

\author{
Gleb Savin* \\ Ural State University of Economics, 8 Marta St., 62, Yekaterinburg, Russia
}

\begin{abstract}
The formation of integrated logistics is the economic mainstream today, which can be characterized by rationality, striving for balance, as well as the predominance of "predatory" instincts for the development of economic agents. At the same time, it is has the features of hedonism and subjectivity, and besides, the evolutionary nature of its influence on the socio-economic system is not fully reflected. Today, the trend of its development is formed with the help of socio-technological drivers of the digital economy and information and communication technologies. So, logistics can be useful in the field of rational choice of optimization, which allows not to break away from the realities in theory. Moreover, digital logistics is already able to offer an achievable vision of the future arrangement in the field of management of flow processes in the modern information space, as well as to determine the optimal paths of evolutionary development.
\end{abstract}

\section{Introduction}

On the one hand, the predominance of the mathematical idyll in the mainstream [1-3] does not always allow determining the essential characteristics of the development of economic theory in a long-term forecast. On the other hand [4-5], without such forecast it is impossible or rather difficult to achieve a positive result in the study of complex systems, since it is characterized by the supremacy of maximum utility for the consumer.

In this perspective, logistics [6-7] prescribes a rational approach to decision making by individuals, which allows taking into account the current time interval characteristic of a given historical period.

Due to existence of different forms of interactions between economic agents, such as a firm (enterprise), connections arise that are primary in logistic theory, and that allow us to consider flow processes as a sequence of routine operations. There are too many of them because of the abundance of firms, for instance loading, unloading, production, and transportation. This causes "friction" that slows down the turnover of economic resources. The development of logistics in the context of orthodox economic theory is aimed at optimizing the flow processes of traditional relations in the aspect of the conceptualcategorial code between the main spheres of the economy [8-9].

* Corresponding author: glebsavin@ya.ru 


\section{Materials and Methods}

Based on the methodological principles of evolutionary economics (monism, synergetics, biological analogy, etc.), it can be noted that integrated logistics uses an interdisciplinary apparatus for the study of complex developing systems [1,3], which is important in the aspect of Schumpeterian competition, the behavior of economic agents and the development of relevant institutions.

Monism, as one of the basic principles of evolutionary development, has unified approaches to the study of socio-economic systems, in which logistics acts as a connecting link of commodity circulation [7], providing the necessary needs, as well as creating a methodological toolkit for obtaining competitive advantages for economic agents. The winner is the one who can adapt and use optimization with the priority of meeting the needs of the end consumer $[6,10]$ whose behavioral features and motives are taken into account, which can be both rational, spontaneous and dependent on society in a certain part of the world (on habits, reflection, etc.).

The motives of each enterprise are different, but the formation of supply chains [11-12] forms their common goal in the interests of the client. There is competition within the chain, which is focused on the selection of the best representatives. In addition, selection is inherent in many supply chains.

Competition launches a transformation in the field of management, approaches and methods of obtaining competitive advantages, while cooperation today takes a more significant role and provides more economic benefits for economic agents.

It is difficult to predict the interactions of economic agents, but with a rational choice, logistics is designed to create an information space and infrastructure that will be beyond their behavior, and will act as the norms and rules of coordination when an adaptive interaction effect is achieved, at the same time it will not determine the uniformity of their behavior.

Natural selection [3] initiates exogenous and endogenous cumulative factors of triggering evolutionary flow processes that affect all spheres of human life. At the same time, with an increase in their number, economic agents should more progressively use new technologies and adaptation mechanisms in order to strengthen their competitiveness.

Changes in connections and interactions with the growth of the adaptive properties of economic agents lead to the transformation of the socio-economic development model. Of course, any self-regulating system that strives for logistic balance [2-4] is not constantly static, but it is focused on technological improvements [7, 10-11], increase of key indicators and productivity. Moreover, its homeostaticity should be reflected in the qualitative indicators of its functioning. This duality of logistics, taking into account the orthodox and heterodox economic theory, makes it possible to assert about the transition of logistics to the digital plane [12], in which a new rational-evolutionary approach is being formed.

This approach is characterized by rationality, which admits strict optimization in certain conditions and in historical retrospective, and by flexibly in the context of emerging contradictions between economic agents.

In addition to generating innovations, this approach involves assessing the cyclical development of global processes in the world, at the reference points of the historical period of which significant structural changes take place.

A new rational-evolutionary approach is formed within the framework of a new syncretic economic paradigm and consists in the formation of a new technological system with an increase in the value of interactions. In this case, digital logistics is designed to form and ensure the functioning; besides it predetermines the further improvement of this system. 


\section{Results and Discussion}

Digital logistics from the standpoint of evolutionary economic theory is designed to expand the methodological tools for studying socio-economic systems through the use of a rationalevolutionary approach. At the same time, adherence to the idea of adaptive rationalization with limited economic resources, Schumpeterian competition and Darwinian economics are designed to clarify its essential content.

In the process of its development, consideration of all economic elements, which are characterized by nonlinearity, stochasticity of behavior and instability, hierarchy, openness, etc. for the socio-economic system, is of great importance from the standpoint of a system approach. Let us highlight the following aspects of the study of digital logistics (Table 1).

Table 1. System approach in digital logistics

\begin{tabular}{|c|c|}
\hline Aspects & Areas of study \\
\hline Complex & Flow processes (evolutionary, smart, development) \\
\hline Structural & Interactions (cooperation and evolutionary selection) \\
\hline Functional & Function of coordination \\
\hline Goal-oriented & 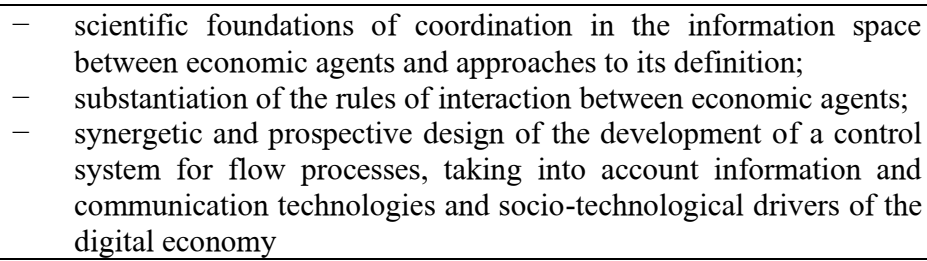 \\
\hline Resource-based & $\begin{array}{l}\text { Change in the structure of appropriations, public-private partnerships } \\
\text { and investments }\end{array}$ \\
\hline Integrative & In the frameworks of socio-economic system \\
\hline Communicational & $\begin{array}{lllll}\text { Interactions within } & \text { Schumpeterian } & \text { Competition and Darwinian } \\
\text { Economics } & & & & \\
\end{array}$ \\
\hline Historical & $\begin{array}{l}\text { The chronological framework of the study is determined by the period of } \\
\text { the beginning of scientific interest in a given problem in the world (from } \\
\text { 1992) to the present. During this reference period, digital technologies } \\
\text { have been actively introduced into the current economic model. }\end{array}$ \\
\hline
\end{tabular}

We agree that the methodological toolkit of digital logistics is complemented by Darwinian ideas of the natural selection when using the comparative genetic approach. It is important not only to select the best solutions implemented in the world in the field of organizing flow processes, taking into account the historical transformation and transmission of the best point mutations, but also to stimulate innovations.

In this situation, the methodology of inter-functional and inter-organizational logistic coordination is of great importance, which permeates the idea of synchronizing the cycles of production, purchase, and sales with the concentration of economic agents in a certain space. Digital logistics creates more open and realistic technological systems focused on the development of infrastructure and a new integrated information management system with the involvement of households and other consumers in making decisions on the management of flow processes, as well as launching its improvement. At the same time, the level of behavior of economic agents in these systems, on the one hand, is determined by traditions and culture in a certain area, but on the other hand, it is also determined by the rational component.

Let's name the disagreements that can be highlighted in the formation of digital logistics, namely the ratio of cooperation and rivalry between economic agents in the socioeconomic system. We call it "primary friction" in the organization of flow processes. 
Due to the fact that this system is in permanent transformation, and also corrects flow processes in real time in a constantly changing internal and external environment, it is possible to single out systemic frictions (Table 2).

Table 2. Systemic frictions in socio-economic system

\begin{tabular}{|c|c|}
\hline Processes & Frictions \\
\hline Evolutionary & $\begin{array}{l}\text { the pursuit of the world economy of constant economic development with a } \\
\text { slowdown in the growth of the quality of human life; } \\
-\quad \text { competition and natural selection; } \\
-\quad \text { an increase in the share of services over material production; } \\
\text { an abundance of digital technologies and technological solutions in the } \\
\text { absence of a rational choice mechanism for the needs of many consumers; } \\
-\quad \text { social and cultural patterns slowing down the introduction of innovations; } \\
\text { mentality and lack of a high degree of trust between economic agents, as } \\
\text { well as reluctance to change; } \\
\text { lag in development and inefficiency of infrastructure operation from the } \\
\text { needs of digitalization. }\end{array}$ \\
\hline Smart & $\begin{array}{l}-\quad \text { inconsistency in the cycles of production, purchase and sale; } \\
-\quad \text { slowdown of material flows in the zones of maximum settlement; } \\
-\quad \text { destruction of traditional methods, approaches and distribution channels; } \\
\text { - } \\
\text { the complexity of creating corporate information systems with distributed } \\
\text { risks based on an open architecture. }\end{array}$ \\
\hline Development & $\begin{array}{l}\text { - the priority of security in the implementation of information and } \\
\text { communication technologies; } \\
\text { - an insignificant role of the state in stimulating the implementation of high- } \\
\text { tech full-cycle industries; } \\
\text { the problem of employment, obtaining new competencies in the digital } \\
\text { economy; } \\
-\quad \text { irrational use of financial resources; } \\
\text { the complexity of the coordination of streaming processes with a variety of } \\
\text { economic agents and their motives of behavior. }\end{array}$ \\
\hline
\end{tabular}

From the viewpoint of the author, digital logistics permeates all levels of logistics relations:

- $\quad$ at the micro level, it provides cross-functional integration;

- $\quad$ at the macro level, it forms a system of interorganizational interaction between supply chains, and also ensures the coordination of actions between economic agents, as well as the process of evolutionary development;

- $\quad$ at the meso-level, it concentrates on the design of a control system for flow processes in the information space with the development of cooperation between the main spheres of the economy;

- $\quad$ at the meta-level, it acts as a scientific knowledge of the rational choice of an alternative to evolutionary development, and also provides conditions for permanent entrepreneurship.

It is important to emphasize that evolutionary economics is characterized by the search for something new, with a counterbalance to the equilibrium paradigm. Digital logistics in these conditions acts as a mechanism for managing flow processes, but at the same time as an initiation mechanism for a rational choice of constant improvements. Besides, it stimulates diversity in its rational choice and adaptive functioning. But if the constant variety of forms of interaction acts as some form of competition while improving quality indicators, then this diversity stimulates innovation, forms new combinations of interactions and contributes to the "creative" destruction of traditional systems and relationships, methods and mechanisms of work. 


\section{Conclusion}

In logistics today, the subject field of research is expanding when consumers are involved in its management, thereby creating feedback and providing an adaptive mode and synergy in managing flow processes, taking into account related areas of knowledge. As a result, socio-economic systems are formed, based on the functioning of which there is a new rational-evolutionary approach.

In the systematic study of processes in these systems, the structure of connections, which ensures the balance of the system, becomes especially important. Undoubtedly, all elements of any system are interconnected and interdependent, each element cannot locally ensure the performance of tasks of a certain nature for the coordinated advancement of streaming processes, they only have a leading role, and the process of achieving goals and objectives is provided by the entire set of functioning elements and links of the system. As a result, coordination as the main function of management in logistics with the development of modern information technologies is also being transformed today, which allows to ensure a higher level of interaction and reduce transaction costs.

The expansion of the essential representation of logistics in the digital field and the formation of transport and logistics systems at the interdisciplinary junction allows us to argue that digital logistics contributes to more progressive interaction between economic agents during the functioning of the system, and also stimulates sustainable development and global partnership.

\section{References}

1. A. Truca, Journal of Economic Methodology, 25, 83 (2018)

2. L. C. Bresser-Pereira, Journal of Post Keynesian Economics, 35, 3 (2012)

3. V.Avtonomov, Y. Avtonomov, Journal of Economic Methodology, 26, 179 (2019)

4. A. Truca, F. Claveauab, O. Santerreac, Journal of Economic Methodology, 28, 67 (2021)

5. S. Dowab, Journal of Economic Methodology, 28, 46-53 (2021)

6. S. Winkelhaus, E. Grosse, Journal of Production Research, 58, 18 (2020)

7. G. Savin, Smart city logistics, E3S Web of Conferences, 208 (2020)

8. A. Nixa, S. Deckerb, Business History, 04, 1 (2021)

9. X. Jiang, Journal of Chinese Economic and Business Studies, 18, 333 (2020)

10. M. Attaran, Supply Chain Forum: An International Journal, 21, 158 (2020)

11. Y. Esmizadeha, M. M. Parastb, International Journal of Logistics Research and Applications, 24, 174 (2021)

12. A. Lagorio, G. Zenezini, G. Mangano, R. Pinto, International Journal of Logistics Research and Applications, 11, 1 (2020) 